\title{
BMJ Open International health research monitoring: exploring a scientific and cooperative approach using participatory action research
}

Tracey Chantler, ${ }^{1,2,3}$ Phaik Yeong Cheah,, ${ }^{4,5}$ George Miiro,, ${ }^{6,7}$ Viriya Hantrakum, ${ }^{5}$ Annet Nanvubya, ${ }^{6,7}$ Elizabeth Ayuo, ${ }^{6,8}$ Esther Kivaya, ${ }^{9}$ Jeremiah Kidola, ${ }^{6,10}$ Pontiano Kaleebu, ${ }^{6,7}$ Michael Parker, ${ }^{5,11}$ Patricia Njuguna, ${ }^{9}$ Elizabeth Ashley, ${ }^{2,4,5}$ Philippe J Guerin, ${ }^{2,4}$ Trudie Lang ${ }^{1,4}$

To cite: Chantler T, Cheah PY, Miiro G, et al. International health research monitoring: exploring a scientific and a cooperative approach using participatory action research. BMJ Open 2014;4: e004104. doi:10.1136/ bmjopen-2013-004104

- Prepublication history for this paper is available online. To view these files please visit the journal online (http://dx.doi.org/10.1136/ bmjopen-2013-004104).

Received 23 September 2013 Revised 29 November 2013 Accepted 4 December 2013

CrossMark

For numbered affiliations see end of article.

Correspondence to Dr Trudie Lang; trudie.lang@ndm.ox.ac.uk

\section{ABSTRACT}

Objectives: To evaluate and determine the value of monitoring models developed by the Mahidol Oxford Tropical Research Unit and the East African Consortium for Clinical Research, consider how this can be measured and explore monitors' and investigators' experiences of and views about the nature, purpose and practice of monitoring.

Research design: A case study approach was used within the context of participatory action research because one of the aims was to guide and improve practice. 34 interviews, five focus groups and observations of monitoring practice were conducted.

Setting and participants: Fieldwork occurred in the places where the monitoring models are coordinated and applied in Thailand, Cambodia, Uganda and Kenya. Participants included those coordinating the monitoring schemes, monitors, senior investigators and research staff.

Analysis: Transcribed textual data from field notes, interviews and focus groups was imported into a qualitative data software program (NVIVO V. 10) and analysed inductively and thematically by a qualitative researcher. The initial coding framework was reviewed internally and two main categories emerged from the subsequent interrogation of the data.

Results: The categories that were identified related to the conceptual framing and nature of monitoring, and the practice of monitoring, including relational factors. Particular emphasis was given to the value of a scientific and cooperative style of monitoring as a means of enhancing data quality, trust and transparency. In terms of practice the primary purpose of monitoring was defined as improving the conduct of health research and increasing the capacity of researchers and trial sites.

Conclusions: The models studied utilise internal and network wide expertise to improve the ethics and quality of clinical research. They demonstrate how monitoring can be a scientific and constructive exercise rather than a threatening process. The value of cooperative relations needs to be given more emphasis

\section{Strengths and limitations of this study}

Addresses a gap in the literature on on-site monitoring in low-income and middle-income settings.

- Lack of focus on and access to quantitative data, which could be collated from monitoring reports and plans, and budgetary documents outlining trial costs.

- Unable to compare the monitoring reports of studies monitored by our case studies and other sponsor delegated monitoring groups.

in monitoring activities, which seek to ensure that research protects human rights and produces reliable data.

\section{BACKGROUND}

In the field of health research the practice of monitoring has become associated with compliance with the 'International Conference on Harmonisation of Technical Requirements for Registration of Pharmaceuticals for Human Use-Good Clinical Practice Guidelines' (ICH-GCP), and related Federal (USA) and European trial regulations. ${ }^{1-4}$ In ICH-GCP, sponsors are delegated responsibility for quality management of which monitoring is an integral component. Monitoring is defined as: The act of overseeing the progress of a clinical trial, and of ensuring that it is conducted, recorded, and reported in accordance with the protocol, Standard Operating Procedures (SOPs), Good Clinical Practice (GCP), and the applicable regulatory requirements. ${ }^{1}$ Section 5.18 of ICH-GCP emphasises that the main purpose of monitoring is to verify that the rights and well-being of human participants are protected. While 
this overarching ethical purpose is reflected in the detailed ICH-GCP guidance, the intrinsic emphasis on record keeping can serve to obscure this primary purpose.

Escalating bureaucracy and regulatory burden is increasing the costs of conducting trials, and deterring researchers from conducting high quality science..$^{5-7}$ While the role of ICH-GCP in improving quality is widely acknowledged there are questions about its' application in health research, specifically in trials not involving investigational medicinal products. ${ }^{8}$ It is argued that the well-intended values and principles of ICH-GCP have become hampered by bureaucracy and misapplication. ${ }^{9}{ }^{10}$ An associated 'tick box' standard is considered to divert attention away from key questions about the ethical process, study endpoints and data validity. Delegating monitoring activities to 'contract research organisations' (CROs) can extenuate this bureaucracy and lead to the misconception that ICH-GCP is highly complex and only achievable with huge resources. ${ }^{9}$ This can be particularly detrimental to research undertaken in low-income and middle-income countries where competitive market forces have resulted in clinical research becoming more driven by profit than local health needs. ${ }^{11}$

ICH-GCP requires that trials should be monitored according to the complexity and nature of the trial. The European Medicines Agency (EMA) and the Food and Drug Administration (FDA) have released new guidance documents, which encourage sponsors to apply a risk and complexity assessment to trials. The aim is to reduce logistical and financial burdens of conducting $100 \%$ data validation. ${ }^{12}{ }^{13}$ This approach was endorsed at the Toronto 'Sensible Guidelines Meeting' in May 2012. ${ }^{14}$ Increasing attention is therefore being paid to rationalising monitoring activities to reflect the risks posed to participants, and to ensure trials generate accurate data to support decision-making about the safety, efficacy or effectiveness of new products and health interventions. ${ }^{15}$

Central statistical monitoring applied remotely through advanced statistical and bioinformatics methods, is proposed as a way of achieving the latter, particularly in multisite trials. ${ }^{16}{ }^{17}$ Baigent et $a l^{17}$ cite the following taxonomy of errors affecting trials (1) design error/procedural error, (2) recording error, (3) fraud and (4) analytical error. They argue that on-site monitoring should target errors, requiring due attention at specific trial sites. Hence central statistical monitoring is not a stand-alone solution but needs to be complemented by proactive on-site monitoring. Experience shows that proactive on-site monitoring (eg, peer review) can enhance the quality of data and trial processes (eg, participant consent). ${ }^{18} 19$

Diverse opinion exists among investigators, sponsors and regulators about the definition and organisation of monitoring. Points of debate are the balance between central statistical monitoring and on-site monitoring, the difference between audit and monitoring and who should undertake these activities. Be it external CROs, in-house pharmaceutical monitors or quality management teams embedded at trial sites. In this discussion there is a dearth of literature from international settings. Macefield et $a l \mathrm{~s}^{20}$ recent systematic review of on-site monitoring methods for healthcare randomised controlled trials was only able to include seven multinational articles. They concluded that there was a paucity of evidence and a need for further evaluation trials.

In our research we evaluated two innovative monitoring models, which are being implemented by Mahidol Oxford Tropical Medicine Research Unit in Thailand and by the East African Consortium for Clinical Research. Our aims were to observe the approach of these models, consider how this could be measured and explore monitors' and investigators' experiences of and views about the nature, purpose and practice of monitoring.

\section{METHODS}

\section{Research design}

We used a case study approach to evaluate the Thai unit's and African consortia's monitoring models in their real life contexts. ${ }^{21}$ The case studies represent interventions, which aim to change and improve practice therefore we applied a participatory methodological approach akin to action research. ${ }^{22}$ Our research team included representatives from the case studies who could act on interim findings during the course of the research. A qualitative researcher, who did not occupy an active or a collaborative role in the monitoring case studies, coordinated the study. The researcher spent 2 weeks with members of each monitoring case study, during these fieldwork visits she observed monitoring activities, participated in a training workshop, reviewed documentary sources and interviewed investigators and monitors associated with the case studies.

\section{Study participants}

The sample was drawn purposively in order to select 'information rich' representatives from two groups: (1) those actively involved in the development, coordination and implementation of the monitoring case studies and (2) investigators and research staff whose work is being monitored by the monitoring case studies. The first group includes monitors and key informants some of who are senior researchers within the Thai programme and the East African Consortia networks. Potential participants were verbally informed about the purpose of the study and related research activities and provided with study information sheet in advance of the researcher's fieldwork visits. At the Thai programme the researcher also presented an overview of the study at the central Thai programme offices. The researcher obtained informed consent from monitors and investigators who were willing to be interviewed and agreed to her observing their research and monitoring activities. Interviewees 
were reassured that their contribution would be kept confidential, and focus-group participants were asked to respect each other's privacy.

A total of 56 participants were recruited (group 1=35 and group 2=21) from the case studies, 26 from the Thai programme and 30 from the East African Consortia. Group 1 comprises 9 key informants (the Thai programme $=5$ and the East African Consortia=4) and 26 (the Thai programme $=6$ and the East African Consortia $=20$ ) monitors. In the East African Consortia case study all of the monitors were also active researchers. Key informants were senior investigators and those with experience of quality management, who had played a significant role in the development of the respective monitoring schemes. Group 2 comprises different cadres of staff: senior investigators (the Thai program=2), site investigators/trial coordinators (the Thai program $=4$ and the East African Consortia $=3$ ) and trial staff (the Thai program $=9$ and the East African Consortia $=3$ ) including some who were specifically responsible for quality control. Table 1 provides details of participants' demographic characteristics. Of note is that the sample includes highly experienced and qualified international research professionals.

\section{Fieldwork}

In April 2012 the researcher visited the Thai programme offices and research facilities in Bangkok and associated research centres/clinics on the Thai-Burmese border (Shoklo Medical Research Unit) and at Pailin District Hospital, Cambodia. All of these research facilities were involved in an antimalarial resistance trial and the researcher was able to observe monitoring activities at each facility. Interviews were held with eight trial investigators, five key informants and six monitors. Two group interviews with members of trial staff based at Thai-Burmese border clinics were conducted, one with two participants and the other with five. Thai and Karen translators helped facilitate the group interviews and two individual interviews with Thai researchers.

\section{Table 1 Participants demographic characteristics}

\begin{tabular}{|c|c|c|c|c|}
\hline \multirow[b]{2}{*}{ Characteristics } & \multicolumn{2}{|l|}{ The Thai Unit $(n=26)$} & \multicolumn{2}{|c|}{$\begin{array}{l}\text { The East African Consortia } \\
(\mathrm{n}=30)\end{array}$} \\
\hline & $\begin{array}{l}\text { Group } 1 \\
\text { (monitors and KIs } n=11 \text { ) }\end{array}$ & $\begin{array}{l}\text { Group } 2 \\
\text { (trial team members) }(n=15)\end{array}$ & Group $1(n=24)$ & Group $2(n=6)$ \\
\hline \multicolumn{5}{|l|}{ Professional background } \\
\hline Medical doctor & 5 & 7 & 10 & 2 \\
\hline Nurse & 2 & 5 & 10 & \\
\hline Other health professional & 1 & 3 & 1 & \\
\hline Biomedical scientist & 3 & & 2 & 1 \\
\hline Social scientist & & & 1 & 3 \\
\hline \multicolumn{5}{|l|}{ Research experience in years } \\
\hline $0-5$ & 1 & 7 & 5 & 3 \\
\hline $6-10$ & 2 & 4 & 14 & 3 \\
\hline $10-20$ & 6 & 2 & 5 & \\
\hline $20+$ & 2 & 2 & & \\
\hline \multicolumn{5}{|l|}{ Gender } \\
\hline Female & 5 & 8 & 14 & 2 \\
\hline Male & 6 & 7 & 10 & 4 \\
\hline \multicolumn{5}{|l|}{ Age range } \\
\hline $18-24$ & 1 & 2 & & 6 \\
\hline $25-44$ & 5 & 10 & 22 & \\
\hline $45-64$ & 5 & 3 & 2 & \\
\hline \multicolumn{5}{|l|}{ Nationality } \\
\hline Bengali & & 2 & & \\
\hline British & 3 & & & \\
\hline Burmese/Karen & & 9 & & \\
\hline Cambodian & & 1 & & \\
\hline Dutch & 1 & & & \\
\hline \multicolumn{5}{|l|}{ French } \\
\hline Indian & 1 & & & \\
\hline Kenyan & 1 & & 11 & 4 \\
\hline \multicolumn{5}{|l|}{ Malaysian } \\
\hline Sudanese & 1 & & 2 & \\
\hline Tanzanian & & & 5 & \\
\hline Thai & 4 & 3 & & \\
\hline Ugandan & & & 6 & 2 \\
\hline
\end{tabular}


In May 2012 the researcher travelled to sites connected with the East African Consortia monitoring case studies and observed a workshop for the East African Consortia monitors. In Uganda she visited the Ugandan Virus Research Institute, the International AIDS Vaccine Initiative and Medical Research Council offices in Entebbe and observed a 2-day monitoring visit of an observational HIV treatment trial at Masaka Referral Hospital. In Kenya she accompanied two monitors on a 3-day monitoring visit of an HIV prevention trial for serodiscordant couples. During the East African Consortia fieldwork six investigators, four key informants and six monitors were interviewed. Three group interviews were conducted with 15 (4, 5 and 6, respectively) monitors during a 2-day monitors training and feedback workshop held in Nairobi in May 2012. This workshop provided rich insights into the challenges and successes experienced by the East African Consortia monitors.

Across both case studies 34 individual interviews were conducted with 12 investigators, 9 key informants and 13 monitors and 2 focus groups with investigators and 3 with monitors. The interviews covered a wide range of topics including the history, purpose and value of the monitoring models, experiences gained and practical and ethical challenges encountered during their implementation and, the definition of monitoring and how to measure or evaluate good practice.

\section{Analysis}

Data constituted of field notes, interview and focus group recordings and transcripts, monitoring reports and other documents relating to the case studies. Recordings were transcribed verbatim with the exception of oral contributions in Thai or Karen. These were translated during the course of the interview and only the English translation was transcribed verbatim. To facilitate the organisation of the data and the development of a coding framework the anonymised data was imported into a qualitative data software program (NVivo V. 10). The recordings and transcripts were crosschecked for accuracy and then TC performed the primary analysis. This involved open coding the interview, focus group and field notes data in a thematic and inductive manner and developing a coding framework. Subsequent analytical meetings with the research team helped refine this framework and led to the definition of two major categories namely; 'the conceptual framing and nature of monitoring', and 'the practice of monitoring', which included reference to relational factors.

\section{CASE STUDY PROFILES}

Case 1: The Thai programme-clinical trials support group The Thai programme is a collaborative partnership between the Faculty of Tropical Medicine, Mahidol University, the University of Oxford and the Wellcome Trust, which was established in 1979 (http://www. tropmedres.ac). The Thai programme's main office and laboratories are located within the Faculty of Tropical Medicine at Mahidol University in Bangkok, Thailand. Clinical trials take place at study sites across Asia and Africa. A 'Clinical Trials Support Group' was established at the Thai programme in 2008 to provide help, guidance and support to investigators conducting research involving human participants. The defining feature and what sets the Thai programme monitoring model apart from standard monitoring models is the way that the clinical trial support group is embedded within an established research unit. This positioning means that its members are familiar with the health research priorities of the unit, can maintain a constant feedback loop between themselves and investigators and understand the diseases and the social context in which trials take place. Additional strengths are that all clinical trial support group members are experienced health researchers and some have worked in the pharmaceutical industry or with CROs. Clinical trial support group members support protocol development, assist with ethics submissions, provide project and data management support, deliver training and assist in the quality management of trials. The latter includes writing trial specific risk-based monitoring plans with investigators and conducting on-site monitoring at defined time points. The Thai programme's monitoring model is not without challenges, however, particularly in relation to workload, travel logistics and ensuring monitoring activities are adequately budgeted for.

Figure 1 illustrates the clinical trial support group's involvement in monitoring a multicentre randomised trial to detect in vivo resistance of Plasmodium falciparum to artesunate in patients with uncomplicated malaria (Web registration number: NCT01350856). This trial is part of the 'Tracking Resistance to Artemisinin Collaboration' (TRAC).

\section{Case 2: The East African consortia reciprocal monitoring model}

The East Africa Consortium for Clinical Research (http://www.eaccr.org) is a partnership of 35 institutions in five countries (Tanzania, Uganda, Kenya, Sudan and Ethiopia). This 'Network of Excellence' is funded by the European and Developing Countries Clinical Trials Partnership and was established in May 2009. At its inception the potential for strengthening monitoring capacity across partner institutions was established as a priority. The vision was to increase capacity for monitoring and develop a pragmatic and cost-efficient networkwide monitoring service. A reciprocal monitoring system was designed and set up in 2007 within Kenya Medical Research Institute-Wellcome Programme in Kilifi Kenya. This novel approach trained study staff to monitor studies and then this pool of trained monitors then spent a small portion of their time monitoring each others' studies within the programme. ${ }^{18}$ This system worked well because it enabled knowledge, best practice and skill sharing between different studies in the same organisation while enabling the implementation of high 

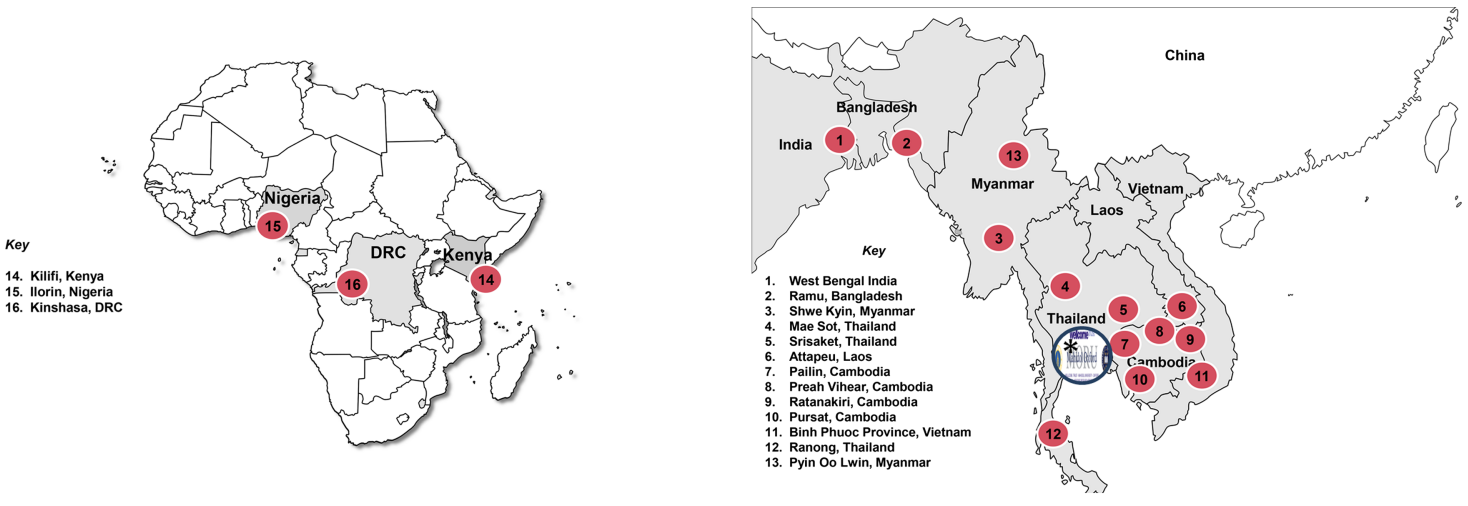

The Thai Unit Monitors based at the Mahidol Research Unit in Bangkok visiting the Artemisinine trial

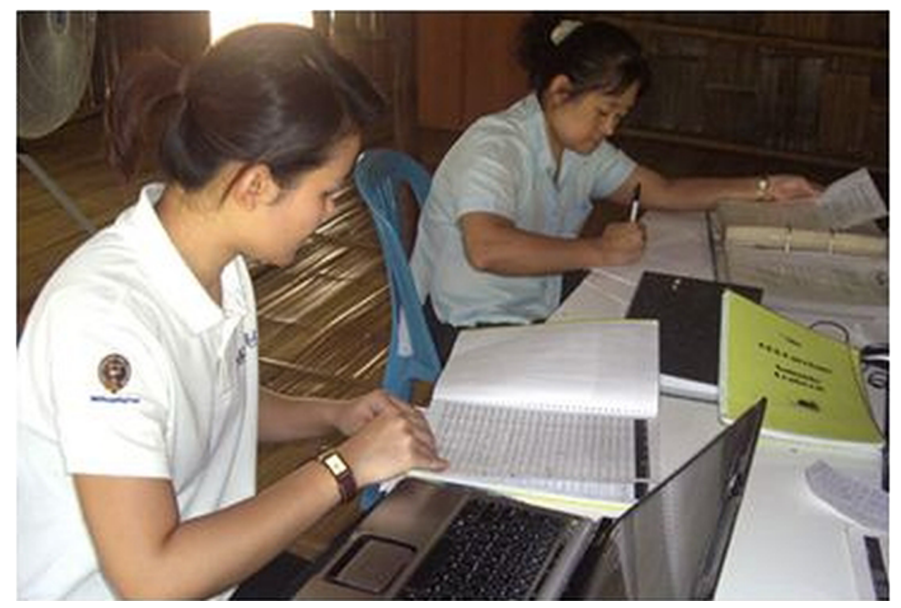

Figure 1 Spatial organisation and infrastructure of clinical trial support group Tracking Resistance to Artemisinin Collaboration (TRAC) monitoring.

quality clinical research monitoring. This approach was then taken up by the East African Consortia and further developed for deployment across this network. This network-wide monitoring approach, which was launched at the start of 2011, is referred to as the East Africa Consortia for Clinical Research Scheme reciprocal monitoring scheme. It involves two coordinators based in Uganda and Kenya and 22 trained monitors nominated by 11 partner institutions (figure 2 ).

The defining features and strengths of the reciprocal monitoring are of course that it is 'reciprocal' and thereby involves, on a part-time basis, health research professionals who have an in-depth appreciation of the context where trials are conducted. It is reciprocal in two key ways; first it involves members of partner institutes monitoring each others' research, second it allows experienced monitors to share their expertise with novice monitors who have limited experience of trial monitoring. Initial challenges have also helped the scheme to improve its logistical functions, and increase its credibility by clarifying the schemes mandate and improving communication between the coordinators and investigators.

\section{FINDINGS}

The accounts given and the observations collected during the fieldwork convey rich information about the nature and practice of on-site monitoring. Accordingly our findings are presented under two main headings; first we explore participants' understandings and expectations of clinical trial monitoring, and then we examine what they think constitutes professional practice with reference to organisational ethos and accountability, monitors' expertise and approach and the focus of monitoring activities.

What is on-site health research monitoring, and what should it be?

We distilled four core elements of monitoring from participants' accounts (figure 3). The latter two are of particular interest because they bring to the fore aspects of 


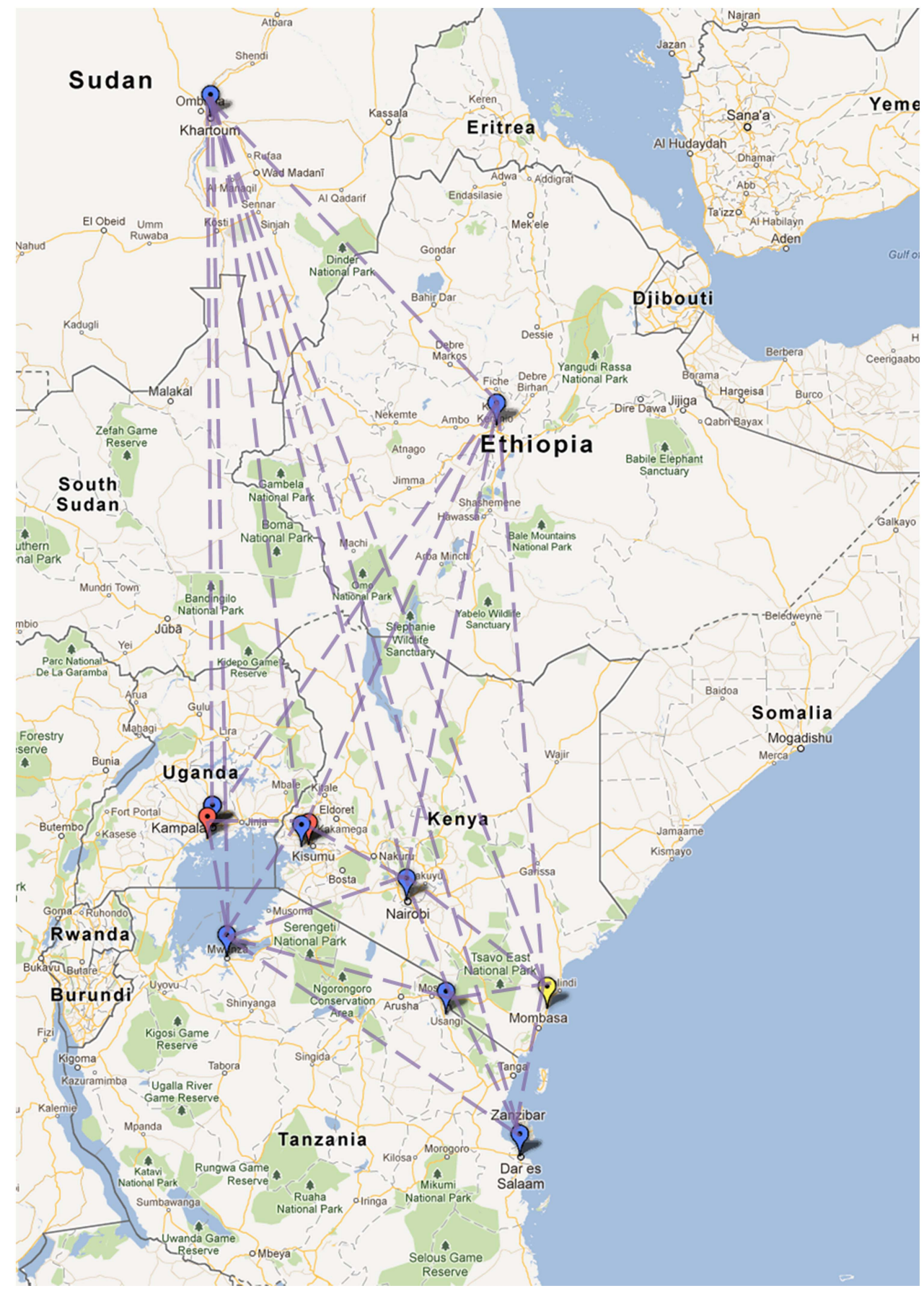

Figure 2 The East African Consortia Partner Institutes involved in the reciprocal monitoring scheme.

monitoring which are often overlooked. Our data suggest that while investigators appreciated the need for regulatory and ethics oversight, they want monitoring to be collaborative in nature and scientific in focus. Some investigators related how constructive interactions with monitors assuaged their initial fears and changed their perceptions about the value of monitoring. Others championed the need for cooperative monitoring as a result of encounters with monitors who questioned their intentions from the outset, or prioritised document verification and paperwork over observing critical research processes.
My first experience was...to me actually I felt it was an activity of policing. I said, "Wow well they are going to find faults,"...I thought maybe it's worth hiding something so that they not know yeah. But with time I came to know really it is something very valuable, that I needed to be involved in. It's actually more to support me into the better conduct of the studies.

Investigator, the East African Consortia 6

I could see that something was, that a monster was being created...this is the whole area of sort of ethics regulation and so and it seemed to be only one direction of travel 


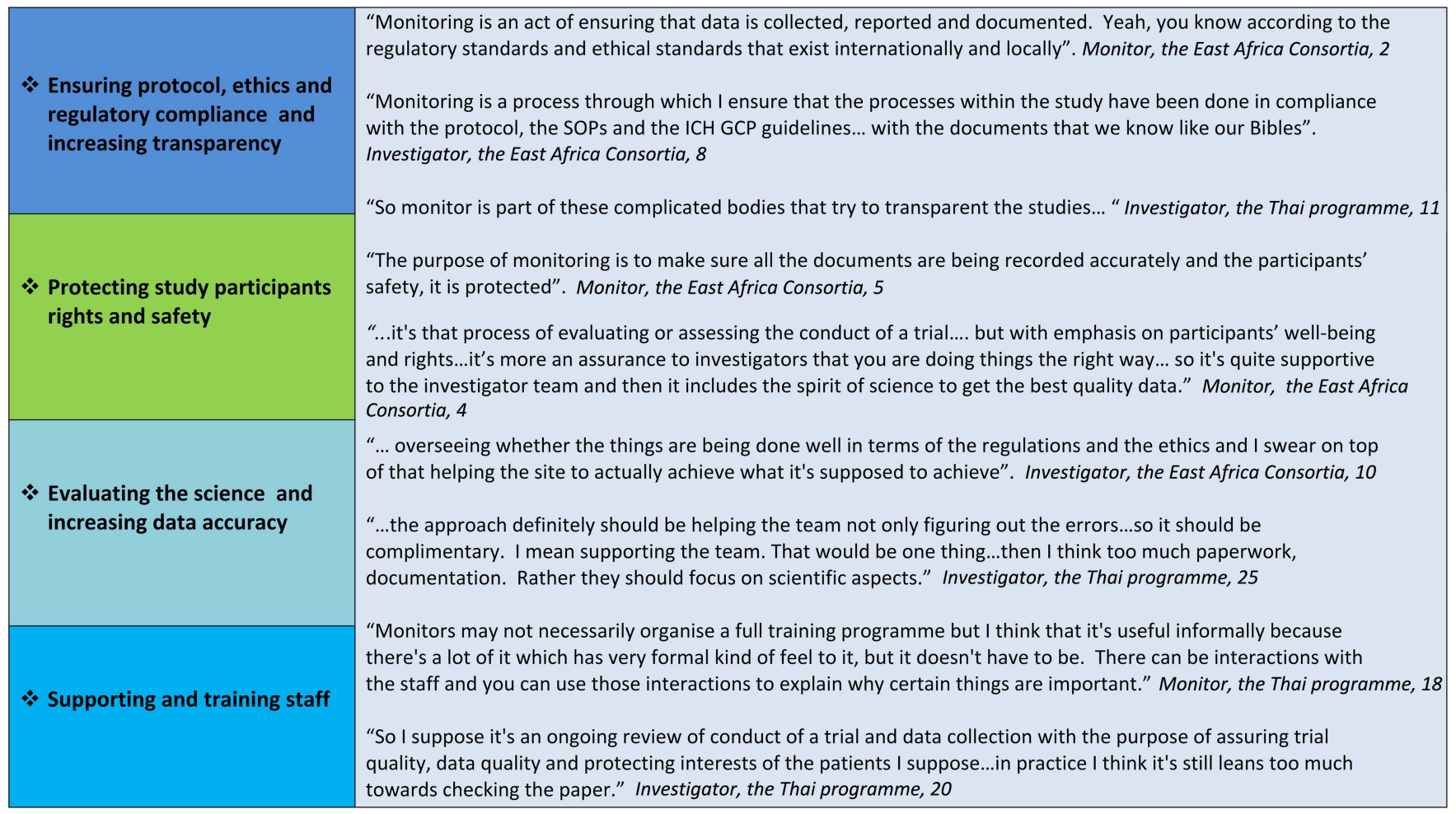

Figure 3 Elements of monitoring.

which was more and more heavy questions and demands and requirements and the net result was more and more paperwork, more and more time devoted towards it.

Investigator, the Thai programme 26

Investigators were keen to be involved in planning monitoring activities and valued the input of monitors who understand what we call the main focus of the study and give credit to the investigator who have long experience (Investigator, the Thai programme 11). They particularly appreciated monitors who worked with them to rectify faults and increase research capacity.

The Thai programme investigators described how the establishment of the clinical trial support group has allowed them to exercise more control over how trials are monitored. They can draw on the expertise of clinical trial support group members to ensure that monitoring activities target the greatest risks to participants and the most scientifically relevant data points. This has helped them develop a counter argument against some of the bureaucracy they believe is hampering the conduct of biomedical research. The East African Consortia reciprocal monitoring scheme was credited with strengthening quality management across the network, and appreciated by monitors as means of professional development and exchange. Across both case studies much value was attributed to a non-threatening 'shared learning' style of monitoring, which prioritised the resolution of problems. ...because it's a sort of cooperative monitoring and not hostile, you're much more likely to get problems sorted out rather than hidden.

Investigator, the Thai programme 17

It was evident that participants wanted monitoring to be scientifically grounded to ensure that quality checks are tailored to primary study outcomes. This type of monitoring requires monitors to work closely with investigators from the planning stages of studies. Much emphasis was also placed on the need to complement checking activities with tailored support and training. Investigators were positive about the need for correction, especially when monitors worked with them to improve their work. Participants concurred that the purpose of monitoring should be to improve the conduct of health research and increase the capacity of researchers and trial sites. In other words monitoring should help sites achieve what they are supposed to achieve and offer assurance to investigators that they are doing things the right way. In practice this type of monitoring replaced negative associations with more positive views of monitoring.

Yeah when a monitor they actually come in to help you do your work better, they're not coming to police you or to find mistakes...they're coming to help you do your work better.

Monitor, the East African Consortia 3 
The practice of monitoring: what constitutes professional practice?

The 'who' of monitoring

Participants' experiences of monitoring suggest that the organisational ethos of monitoring bodies has a bearing on the practice of monitoring. It was evident from participants' accounts that monitors from external bodies sometimes distanced themselves from research staff. In contrast the East African Consortia monitors conveyed the notion we are doing this together, similarly the positioning of the clinical trial support group as an internal monitoring group within the Thai programme enhanced interactions between researchers and monitors and increased transparency. On the other hand some Thai programme investigators felt that research staff were more alert and ready during monitoring visits from external groups.

These observations about interactions between monitors from different organisations and investigators raise important points about accountability and professional relationships. The East African Consortia monitors, for example, argued that monitors can identify with the site while remaining accountable to the study sponsor, and the Thai programme investigators maintained that the positioning of the clinical trial support group does not pose a conflict of interest. To the contrary they work together more easily because their professional relationship is built on trust and mutual understanding. According to a study nurse this prior knowledge reduced the stress associated with monitoring but it did not alter the need for correction. Internal monitors applied the same standards as external monitors but their proximity meant that they were more accessible and could provide on-going support.

Yeah for me I think it's not so hard because it's not like the investigator is against the sponsor. So it's not like they're trying to identify with you as opposed to the sponsor. They're just when they are on the site they're talking we. We can do this... and the way I see it, it's not hard for them to identify with the site.

Monitor, the East African Consortia, 27

Clinical trial support group they will know the protocol very well and they will know us quite well I have to admit it, but that doesn't provide conflict of interest...in a way it make us work together easier.

Investigator, the Thai programme, 11

Monitors' background, training and expertise and their understanding of the research context were viewed as important in terms of professional practice. One investigator said that he judged the value of monitors' work by the quality of the information they are able to detect (Investigator, the East African Consortia 7). Health professionals with experience of working in research were regarded as particularly well equipped to be monitors. A role, which was also thought to require motivation and commitment, attention to detail, good interpersonal and communication skills and the ability to apply and interpret ethics guidelines in practice. With reference to the latter an investigator emphasised that monitors needed to understand the scientific purpose of the research in order to think about the patient's interests and how they could advocate for those, or how they could check for those (Investigator the Thai programme, 20).

Much value was attributed to context informed monitoring and investigators resented monitors who did little to consider cultural norms, logistical limitations and local regulations.

They come and they have such little time and they will have to do so much so they're in a rush and sometimes they're really distressed to try and meet their milestones. And then the other thing that I have seen is inability to understand the culture and even local regulations sometimes, harmonising and local regulations and sponsors, SOPs and their own regulations back in their country, it's such a big issue. So they come out and they would like things done the way they understand it. A few times we took it upon ourselves to really train them on our culture, what is acceptable, what cannot be done.

Investigator, the East African Consortia, 10

This investigator is arguing that an appreciation of local norms, customs and regulations is a prerequisite for effective and professional monitoring practice. Local monitors were considered well placed to undertake context informed monitoring and external monitors who demonstrated a willingness to learn rather than simply impose ideas were also highly valued. When it comes to the 'who' of monitoring what counts is mutual respect, communication, professionalism and maintaining high standards irrespective of the positioning of the monitor with regard to the sponsor and researcher.

\section{The 'what' and 'how' of monitoring}

When it came to the practicalities of monitoring what counted was getting the focus and the approach right. Focus requires careful planning and clinical trial support group participants stressed the importance of developing monitoring plans with investigators. This planning helped them to identify the main risks to a study's integrity with reference to ethics and key study outcomes. It helped them differentiate between minor and major errors thereby avoiding diverting unwarranted time to rectifying the former. Focus also involves achieving the right balance between paper work and observing research in practice.

I mean sometimes documents don't, may not give, tell you, give you, the clear picture of how things are run. Sometimes talking to people, asking people questions, seeing what people are doing can assure you, can tell you a number of things that you can't see by looking at the documents.

Key informant, the East African Consortia, 28 
Concerns were raised by investigators about the amount of time monitors (coming from long distances) end up spending sitting in rooms verifying files and source documents. It was argued that on-site monitoring should not be confined to document review but include observational and interactive activities, which allow monitors to gain greater insights into how a trial is being implemented and where corrective action is needed.

Two distinct ways of organising monitoring activities were described. One where the monitor performs their review, presents findings in debriefing meetings and sends a summary report with action points; and the other where the monitor actively engages research staff in resolving issues during the on-site visit. The components of monitoring visits were similar but the engagement differed. Investigators not only expressed preference for the latter but also noted that this method was time-consuming and impractical when the research clinics are busy.

A monitor's personal and professional approach was viewed as crucial in promoting positive interactions and improving the quality of trials.

The key thing about successful monitoring is how you present, how the monitor presents themselves and involves themselves with the investigators

Investigator, the Thai programme, 26

Monitors need to gain the trust of investigators and interviewees argued that the best way to do this is to work with investigators to improve study conduct. It was evident that investigators were anxious about discussing problems or disclosing important information to overly critical monitors. One investigator (Investigator, the East African Consortia, 7) described how his team's fear just melted away when they realised that their monitor's approach (an external CRO monitor) was not adversarial you did this wrong, we are going to beat you, but constructive he's like trying to make you improve.

The core features of a professional approach to monitoring were cited as a commitment to high standards, open communication and positive interactions, mutual respect and a friendly manner. Investigators appreciated monitors who maintained high standards in a strict and firm manner and worked with them to enhance the quality of their work.

\section{DISCUSSION}

Our participatory evaluation provides important insights about the practice of international on-site monitoring, and the value of utilising internal and network expertise to enhance trial quality. Particular emphasis was given to a cooperative style of monitoring as a means of enhancing trust and transparency. While this style of monitoring was associated with the East African Consortia and the Thai programme models, it is important to note that some participants commented positively on interactions with CRO monitors. With reference to practice, our findings suggest that the primary purpose of on-site monitoring is to improve the conduct of health research and increase the capacity of researchers and trial sites. Monitoring activities to be scientifically grounded, contextually and culturally informed with tailored support and training. Skills in the scientific evaluation of trials and a willingness to work closely with investigators were viewed as critical for the development of effective risk-based and context-informed monitoring plans. It was argued that on-site monitoring should combine document verification with observational activities, and be complemented by training and mentoring to enable investigators to execute necessary corrective actions. Indeed our data suggest that the success of monitoring should be measured by corrective action rather than by identification of faults. Monitoring reports should only include findings, which could significantly impact the scientific and ethical integrity of the trials.

The main benefits of the Thai programme and the East African Consortia monitoring models are: (1) reduced logistical costs, (2) increased site capacity for quality management, (3) investigators contribution to risk-based monitoring and plans, (4) professional development and exchange. The latter is of relevance given the increased value attributed in the health sector to 'Communities of Practice' as a means of encouraging situated learning and the practical application of knowledge. ${ }^{23}$ Communities of practice are defined as: groups of people who share a concern, a set of problems, or a passion about a topic, and who deepen their knowledge and expertise in this area by interacting on an on-going basis. ${ }^{24}$ The challenges relate to questions of sustainability and credibility. There is a need to consider the logistics and funding of these models to ensure that their benefits are sustainable. Currently both models rely heavily on grants rather than charging trials directly for their services. This needs to be remedied in order to reduce dependency on external funding.

The strengths of this empirical study are that it contributes to the literature documenting good practice at international trial sites in resource-constrained settings. As noted in the background section Macefield et $a l^{20}$ were only able to include seven multinational trials in their systematic review. Given the study design one inherent limitation is the paucity of quantitative findings. Follow-up studies will need to systematically collate information on trial costs, and provide monitoring report templates. An additional weakness of our work is that we were not able to compare the monitoring reports of studies monitored by the Thai programme and the East African Consortia reciprocal monitoring scheme, and other sponsor delegated monitoring groups. A key area for future research will be to conduct a mixed methods 
study, which evaluates how the East African Consortia and the Thai programme on-site monitoring models work in combination with central monitoring systems.

\section{CONCLUSIONS}

Innovative monitoring models, which prioritise the sensible application of regulations and ethical guidelines are imperative to facilitate vital global health research. The experience gained in developing the innovative international models studied in this paper offers valuable insights and examples of alternative approaches. Both models utilise internal and network wide expertise to improve the ethical conduct and data quality of clinical research. They demonstrate how monitoring can be a constructive exercise rather than a threatening process. The value of cooperative relations needs more emphasis in this field given that sponsors, investigators and monitors are jointly responsible for ensuring that research protects human rights and produces reliable data, which can improve human health.

\author{
Author affiliations \\ ${ }^{1}$ Nuffield Department of Clinical Medicine, The Global Health Network, Centre \\ for Tropical Medicine, University of Oxford, Churchill Hospital, Oxford, UK \\ ${ }^{2}$ Nuffield Department of Clinical Medicine, Worldwide Antimalarial Resistance \\ Network (WWARN), Centre for Tropical Medicine, University of Oxford, \\ Churchill Hospital, Oxford, UK \\ ${ }^{3}$ Nuffield Department for Population Health, The George Institute for Global \\ Health, University of Oxford, Oxford, UK \\ ${ }^{4}$ Nuffield Department of Clinical Medicine, Centre for Tropical Medicine, \\ University of Oxford, Churchill Hospital, Oxford, UK \\ ${ }^{5}$ Mahidol Oxford Tropical Medicine Research Unit, Faculty of Tropical \\ Medicine, Mahidol University, Bangkok, Thailand \\ ${ }^{6}$ East African Consortium for Clinical Research, Uganda Virus Research \\ Institute, Entebbe, Uganda \\ ${ }^{7}$ Ugandan Virus Research Institute, Entebbe, Uganda \\ ${ }^{8}$ Kenyan Medical Research Institute, Centre for Global Health Research, \\ Kisumu, Kenya \\ ${ }^{9}$ Kenyan Medical Research Institute, Centre for Geographical Medicine \\ Research-Coast CGMRC, Kilifi, Kenya \\ ${ }^{10}$ National Institute for Medical Research, Mwanza Research Centre, Tanzania \\ ${ }^{11}$ Nuffield Department of Population Health, The Ethox Centre, University of \\ Oxford, Oxford, UK
}

Acknowledgements The authors thank Richard Cooksey for technical assistance in developing figure 2, Kayla Laserson for commenting on the manuscript, Holly Blades for proof reading, Sam Franzen for his help with organising the references, Jatee Wichjtponpaibun for her contribution and members of the Thai programme and the East African Consortia monitoring models for sharing their experiences to date. The authors would also like to thank the Worldwide Antimalarial Resistance Network, The Global Health Network and the Bill \& Melinda Gates Foundation for supporting this review of innovative monitoring models. This work has been published with the permission of the Kenya Medical Research Institute (KEMRI) Director.

Contributors All authors participated in the study design from conception. TC conducted the case study fieldwork with the support of AN, EA, GM, EK, PYC and VH. TC performed the primary analysis and TL was involved in subsequent analytical review and decision-making. TC wrote the first draft of this paper and all authors critically revised the manuscript.

Funding This research received no specific grant from any funding agency in the public, commercial or not-for-profit sectors.
Competing interests MP's work in global health ethics is supported by a Wellcome Trust Strategic award (096527).

Ethics approval The study was approved by the Oxford Tropical Research Ethics Committee (Ref: 09-12), the Kenyan Medical Research Institute Ethics Review Committee (No: 2253), the Ugandan Virus Research Institute Science and Ethics Committee (Ref: GC/127/12/03/04), and the Ethics Committee of the Faculty of Tropical Medicine, Mahidol University (Ref TMEC 12-023).

Provenance and peer review Not commissioned; externally peer reviewed.

Data sharing statement The protocol is provided along with this paper. All the data collection tools, templates and data will then be made available on

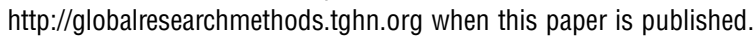

Open Access This is an Open Access article distributed in accordance with the Creative Commons Attribution Non Commercial (CC BY-NC 3.0) license, which permits others to distribute, remix, adapt, build upon this work noncommercially, and license their derivative works on different terms, provided the original work is properly cited and the use is non-commercial. See: http:// creativecommons.org/licenses/by-nc/3.0/

\section{REFERENCES}

1. International Conference on Harmonisation of Technical Requirements for Registration of Pharmaceuticals for Human Use. Guideline for Good Clinical Practice E6(R1). 1996. http://www.ich. org/fileadmin/Public_Web_Site/ICH_Products/Guidelines/Efficacy/ E6_R1/Step4/E6_R1_Guideline.pdfInternational (accessed 21 Sep 2011).

2. US Food and Drug Administration. FDA regulations relating to good clinical practice and clinical trials. 2012. http://www.fda.gov/ ScienceResearch/SpecialTopics/RunningClinicalTrials/ucm155713. htm-FDARegulations

3. European Medicines Agency. Regulatory and procedural guidance index. 2012. http://www.ema.europa.eu/ema/index.jsp?curl=pages/regulation/ general/general_content_000316.jsp\&mid=WC0b01ac05800a4902

4. Yusuf S, Bosch J, Devereaux PJ, et al. Sensible guidelines for the conduct of large randomized trials. Clin Trials 2008; 5:38-9.

5. McMahon AD, Conway DI, MacDonald TM, et al. The unintended consequences of clinical trials regulations. PLoS Med 2009;6: e1000131.

6. Eisenstein EL, Collins R, Cracknell BS, et al. Sensible approaches for reducing clinical trial costs. Clin Trials 2008; 5:75-84.

7. Duley L, Antman K, Arena J, et al. Specific barriers to the conduct of randomized trials. Clin Trials 2008;5:40-8.

8. Lang T, Siribaddana S. Clinical trials have gone global: is this a good thing? PLoS Med 2012;9:e1001228.

9. Lang T, Cheah PY, White NJ. Clinical research: time for sensible global guidelines. Lancet 2011;377:1553-5.

10. Grimes DA, Hubacher D, Nanda K, et al. The good clinical practice guideline: a bronze standard for clinical research. Lancet 2005;366:172-4.

11. Foster C, Malik AY. The elephant in the (board) room: the role of contract research organizations in international clinical research. Am $J$ Bioethics 2012;12:49-50.

12. US Department of Health and Human Services Food and Drug Administration. Guidance for industry oversight of clinical investigationsa risk-based approach to monitoring (draft guidance). New Hampshire: Food and Drug Administration, 2011 http://www.fda.gov/

ScienceResearch/SpecialTopics/RunningClinicalTrials/Proposed RegulationsandDraftGuidances/default.htm (accessed 7 Oct 2011).

13. European Medicines Agency. Reflection paper on risk based quality management in clinical trials (draft for comments). 2011. http://www. seg-web.org/index.php/lang-en/dernieres-nouvelles/86-emea/187-emadonner-votre-avis-sur-un-document-de-reflexion-concernantla-gestion-de-la-qualite-dans-les-essais-cliniques (accessed 7 Oct 2011).

14. Duke Translational Medicine Institute. Symposium on the Sensible Guidelines for the Conduct of Clinical Trials-May 24/25 2012. 2012. http://www.dtmi.duke.edu/news-publications/upcoming-events/ symposium-on-the-sensible-guidelines-for-the-conduct-ofclinical-trials-may-24-25

15. Clinical Trials Transformation Initiative. Developing effective quality systems in clinical trials: an enlightened approach (summary of an expert meeting). 2010. http://www.trialstransformation.org/projects/ effective-and-efficient-monitoring/Workstream3 (accessed 4 Oct 2011). 
16. Venet D, Doffagne E, Burzykowski T, et al. A statistical approach to central monitoring of data quality in clinical trials. Clin Trials 2012;9:705-13.

17. Baigent $\mathrm{C}$, Harrell $\mathrm{FE}$, Buyse $\mathrm{M}$, et al. Ensuring trial validity by data quality assurance and diversification of monitoring methods. Clin Trials 2008:5:49-55.

18. Chilengi R, Ogetii G, Lang TA. A sensible approach to monitoring trials: finding effective solutions in-house. Webmed Central Clin Trials 2010;1:WMC00891.

19. Lane JA, Wade J, Down L, et al. A peer review intervention for monitoring and evaluating sites (PRIME) that improved randomized controlled trial conduct and performance. J Clin Epidemiol 2011;64:628-36.
20. Macefield RC, Beswick AD, Blazeby JM, et al. A systematic review of on-site monitoring methods for health-care randomised controlled trials. Clin Trials 2013;10:104-24.

21. Yin RK. Case study research: design and methods. 4th edn. London: Sage, 2009.

22. Stringer ET. Action research: a handbook for practitioners. Thousand Oaks, California: SAGE, 1996.

23. Li L, Grimshaw J, Nielsen C, et al. Use of communities of practice in business and health care sectors: a systematic review. Implementation Sci 2009;4:27.

24. Wenger E, McDermott R, Snyder W. Cultivating communities of practice. Boston, MA: Harvard Business School Press, 2001. 